\title{
JEAN-BAPTISTE DU TERTRE: EXPLORADOR Y MISIONERO DE LA CORTE DE RICHELIEU
}

\author{
VINCENZO LAGIOIA \\ UNIVERSITÀ DI BOLOGNA
}

\begin{abstract}
RESUMEN
Desde el siglo XV hasta finales del XVII los debates religiosos entorno a la llamada "savane" ocupan un amplio espacio en las páginas de los textos de exploradores y misioneros, además de ser el centro de las conversaciones en los salones refinados de toda Europa. El asunto de estos debates aparece como uno de los grandes temas filosóficos, históricos y antropológicos del momento, importante no sólo para la identificación y la definición de regiones remotas, todavía desconocidas, sino también para la comprensión de la misma naturaleza humana y la revisión de las certezas tradicionales. El historiador Du Tertre, fiel a las obligaciones epistemológicas de un "research", defiende desde su obra escrita la profesión de historiar marcada por "la veracidad y la sinceridad". En su De la Religión des Sauvages, sigue la metodología del historien, atento a las relaciones con respecto a la flora, la fauna y los movimientos políticos de las Islas, las cuales describe con gran exhautividad en la primera parte de dicho texto. A él dedicamos nuestra atención en el presente estudio.
\end{abstract}

\begin{abstract}
Starting from the Fifteenth century, up to including, all of the Seventeenth century, the discussion of the religion of the so-called "savane" occupies ample space throughout the pages of the texts of explores and missionaries and was at the heart of conversations at the refined salons al lover Europe. It appears as one of the great philosophical, historical and anthropological themes and is important not only for the identification and the definition of remote regions that are still unknow but also for the comprehension of human nature itself and the revision of traditional certainties. Faithful to the epistemological obligations of a dispassionate resaerch of historical truth and constant in the profession of that "veracity and sincerity" which has been difende since the creation of the work, in the tract, De la Religion des Sauvages, Du Tertre remains the methodological historien who is attentive to the relations regarding the flora, the fauna and the political movements of the Islands which he descrive with great assiduousness in the first part of his work.
\end{abstract}

PALABRAS CLAVES: Misioneros, exploración, Francia, orden de los dominicos, Nuevo Mundo

KEY WORDS: Missionaries, exploration, France, Dominican Order, New World 
Quoy qu'en vérité nos Sauvages ne soient Sauvages que de nom, ainsi que les plantes et les fruits que la nature produit sans aucune culture dans les forêts et dans les déserts, lesquelles quoi que nous les appelions Sauvages, possèdent pourtant les vraies vertus et les propriétés dans leur force et dans leur entière vigueur, que bien souvent nous corrompons par nos artifices, et altérons beaucoup, lors que nous les plantons dans nos jardins ${ }^{1}$.

Nació en Calais y falleció en París, después de vivir unos años en las Antillas: esta es la vida de Jean-Baptiste Du Tertre ${ }^{2}$, un misionero dominico que vivió en el siglo de Luis XIV, en el período de máximo esplendor de la Francia que Charles Le Brun celebró en las bóvedas de la Grande Galérie de Versailles; aquella Francia majestuosa que Hyacinthe Rigaud representó como en una memoria eidética con el famoso retrato de Luis XIV; y de la que Voltaire consagraría el arquetipo en el Siècle de Louis XIV.

Du Tertre, misionero dominico, ante todo es francés. Su biografía intelectual y su experiencia eclesiástica, tan ricas de acontecimientos extraordinarios y significativos, realmente podrían representar un capítulo especial de aquella "crisis de la conciencia europea" de la que Paul Hazard ${ }^{3}$ nos ha dejado un análisis eficaz y apasionante. Su biografía se entrelaza con la "gran historia" de forma significativa. Después de una experiencia de vida militar, Du Tertre entra en la orden de Predicadores en 1635, a los 25 años, una edad ya avanzada: normalmente los candidatos a la vida religiosa ingresaban mucho antes, en general en la temprana adolescencia, una edad que permitía llevar a cabo en las escuelas de la Orden los estudios de bachillerato y luego la admisión al estado clerical y el ingreso a las órdenes mayores. Du Tertre, en cambio, ya había tenido varias experiencias de vida, por lo que su carrera religiosa se configura más bien como una elección y una vocación madura que como un destino o una obligación social. Sin embargo, también en la orden de Predicadores diferentes acontecimientos históricos y complicadas vicisitudes interiores atormentan su vida en los años cruciales de la primera mitad del siglo XVII.

En la Orden, desde el punto de vista jurídico Du Tertre pertenece a la congregación de san Luis, que algunos años más tarde se convertirá en una

1. J.B. DU TERTRE (1654), 396.

2. I. Guet-Michaud (1893), 394; P. Fournier (1932), 35; E. Bourgeois y A. Louis (19131935), 67-68.

3. P. HAZARD (1961). 
provincia de la región de Occitania. Precisamente en estas tierras en junio de 1636 estalla la rebelión de los llamados croquants, que luego se extenderá rápidamente al Oeste y Suroeste. Recién ordenado sacerdote, Du Tertre viaja a las Antillas, donde se quedará durante un largo período, con una interrupción de 1640 a 1647 . En $1654^{4}$ se encuentra otra vez en París, en el convento designado como Noviciado General de toda Francia por el mismo Maestro de la Orden, donde se dedica a la publicación de su obra, la Histoire générale des isles de S. Christophe, de la Guadeloupe, de la Martinique et autres dans l'Amerique, où l'on verra l'establissement des colonies françaises dans ces is$l e s^{5}$, gracias a la que se ganó la fama de nuevo Hérodote des Antilles ${ }^{6}$. La obra se volvió a publicar en los años 1667-1671 con amplias integraciones bajo el título Histoire générale des Antilles habitées par les François?

Se trata de una obra enciclopédica por su diseño y estructura, que concreta de forma extremadamente clara el objetivo patriótico que había inspirado la redacción de los volúmenes, el proyecto político que había validado su utilidad, así como el método en que se apoyaba toda la investigación. Así, entre el amor por Francia y el amor por la verdad, Du Tertre reitera firmemente que la única "pasión" que lo ha sustentado en la redacción del texto es la de servir a la patria proporcionando a los gobernadores franceses de las colonias de ultramar un patrimonio de conocimientos y consejos útiles para gobernarlas y conservarlas. Y reivindica con fuerza "la veracidad y la sinceridad" de la obra misma, en una especie de reflexión sobre el método historiográfico rápido y eficaz que prescribe los cánones de un riguroso conocimiento histórico especificando las herramientas adecuadas: los testimonios directos y los documentos fidedignos. El saber histórico, por lo tanto, no procede de la fantasía de los cuentos, de la voz de la tradición o del peso de la autoridad, sino de la evidencia de la observación y de los testimonios de fuentes originales y acreditadas. Por otra parte, la historia persigue la epifanía de diseños divinos, y no ofrece modelos ejemplares curiosos o aleccionadores, sino hechos y choses, como él afirma, cuyo conocimiento "verídico y sincero", según la acertada hendíadis acuñada por Du Tertre, puede y tiene que inspirar una acción política y administrativa razonable y eficaz.

4. A. Mortier (1903-1920), vol. VII, 43.

5. J.B. DU TERTRE (1654).

6. El padre Du Tertre es definido como el Hérodote des Antilles en el artículo "Les Dominicains aux Antilles", Année dominicane, 1932, 13-18.

7. J.B. DU TERTRE (1667-1671). 
La obra ofrece una documentación científica y antropológica única sobre las Antillas y una crónica detallada de los acontecimientos de ese tiempo, que incluso fueron retomadas y reelaboradas posteriormente por otros autores; entre estos uno de los primeros fue Jean Baptiste Labat ${ }^{8}$. Sin embargo, desde el principio la obra también sufre plagios y refundiciones por parte de contemporáneos de Du Tertre, como por ejemplo César de Rochefort ${ }^{9}$. Tanto es así que Montmore, uno de los notables de la Assemblée des Physiciens, Mathématiciens et Astronomes, pide a Du Tertre que vuelva a trabajar en su obra para profundizarla e integrarla donde sea necesario.

Se trata de la historia de las Antillas en el sentido clásico de descripción completa y detallada de la geografía de estas islas, de los aspectos naturalistas, de las determinaciones ambientales y de los rasgos antropológicos de sus habitantes. La obra está dividida en dos volúmenes, el primero contiene la descripción detallada de todos los asentamientos de las colonias francesas en las Antillas ${ }^{10}$, en la que se dedica amplio espacio a consideraciones de

8. Jean-Baptiste Labat (1663-1738), misionero dominico, botanista, etnógrafo, militar, ingeniero. Su vida fue una novela de páginas inmortales hasta el punto de que ofuscó completamente la figura de Du Tertre. El vasto trabajo del misionero, Nouveau voyage aux iles de l'Amérique contenant l'histoire naturelle de ces pays, l'origine, les moeurs, la religion et le gouvernement des habitants anciens et modernes, les guerre set les événements singuliers qui y sont arrivés pendant le séjour que l'auteur y a fait, publicado en 6 volúmenes en París en 1722, vuelve a presentar las historias de los asentamientos de las colonias franceses y la historia natural y social de los nativos con un anecdotario peculiar que se convertiría en la principal característica del autor. Se involucró en primera persona en aventuras militares, lo que dejó perplejos a sus superiores, y sin embargo contribuyó a originar el mito del buen salvaje.

9. El plagiaire en cuestión es el ministro de Rotterdam, César de Rochefort. Catalogue Général des livres imprimés de la Bibliothèque Nationale, París 1938. La obra a la que se hace referencia es la Histoire naturelle et morale des iles Antilles de l'Amerique avec un vocabulaire caraibe, 1658. En el mismo lema, los editores escriben "cet ouvrage est attribué au P. Jean-Baptiste Du Tertre, le Vocabulaire caraibe pourrait être du P. Breton".

10. El volumen I se abre con una reflexión de carácter psicológico, relaciona los peligros y las dificultades de las conquistas del Nuevo Mundo con el deseo de riquezas que inspira las acciones más atrevidas de los hombres. "Ce n'est pas d'aujourd'hui" escribe Du Tertre con su crudo realismo que consigue omitir cualquier tentación moralizante "que l'or et l'argent ont fait de fortes impressions sur l'esprit des hommes, et que le desir de posseder des richesses, leur a fait mépriser les plus grands dangers et entreprendre les choses les plus difficiles". Así, a partir de 1493, el año en que Colón descubrió América, "les richesses immenses de ce nouveau monde animerent toutes les Nations à leur conqueste et il n'y en eut pas une qui ne voulut partager avec les Espagnols, un butin si riche et si precieux". El riguroso cronista Du Tertre, de hecho recuerda que "le pape Alexandre VI par al Bulle de l'an 1493 ayant donné tout ce grand pays aux Roys Catholiques Ferdinand et Isabelle, les Roys d'Espagne en vertu de cette donation pretendirent en etre les seuls possesseurs legitimes; et sous ce preteste tratterent comme des corsaires tous ceux qui furent trouvez entre les deux Tropiques. Mais ny la concession du Souvrain Pontifice, ny la cruauté barbare des Espagnols, ne purent empecher les etrangers de faire voiler en l'Amerique, pour tacher de s'y enrichir". Así actuaron los franceses, que repoblarían, fortificarían y 
estrategia militar y especial atención a los hechos de la política, tanto en tiempo de paz como en tiempo de guerra. La descripción viene acompañada por una imponente cantidad de importante material histórico -concesiones reales, cartas-patentes, lettres de cachet, comisiones del Rey, deliberaciones de la Compañía... - por lo que sin duda se puede considerar un documento fundamental para reconstruir rigurosamente las vicisitudes políticas y militares de las Antillas y para contextualizarlas en el más amplio cuadro internacional de aquella época tan atormentada. El segundo volumen, que está dividido en ocho tratados, presenta una "historia natural" exhaustiva de las Antillas, que abarca muchas disciplinas, de la geografía a la botánica y la zoología, hasta la antropología. El volumen también incluye las memorias del último viaje de Du Tertre y algunas informaciones del padre Feuillet, con imágenes de gran realismo, documentos no verbales frutos de la observación científica que lo completan proporcionando más detalles. Se trata de ilustraciones científicas: algunas reproducen varios ejemplares naturalistas dibujados con extrema precisión y gran atención al detalle; otras representan escenas de la vida cotidiana, reproducidas con riguroso cuidado en la veracidad histórica y antropológica, según aquella interpretación del canon histórico -descripción naturalista y narración de acontecimientos- que Du Tertre adopta y defiende a lo largo de toda su obra.

Sin embargo, también puede considerarse una historia de las Antillas en el sentido más moderno de crónica de los principales acontecimientos históricos, puesto que se basa en los testimonios directos del autor y en las informaciones recogidas en las sedes oficiales de las colonias, así como en las encuestas que Du Tertre realizó personalmente con los nativos o que recibió de los directores de la Compagnie des Iles d'Amerique, refundada por el cardenal Richelieu en $1635^{11}$. La Histoire es un documento histórico de primer

evangelizarían las islas conquistadas: "ces differens establissement serviront de matiere à la premiere partie de cette Histoire, dans la quelle je prétens representer les difficultez dont ils ont eté acompagnez, les manquemens qui s'y sont commis, les obstacles qui s'y sont rencontrez, les Compagnies qui les ont entrepris, les divers traittez qui ont eté faits, tant avec les habitans, qu'avec les sauvages, les combats qui s'y sont donnez enfin tout ce qui s'est passé de particulier, soit en paix, soit en guerre, dans toutes les Ant-Iles habitées maitenant par les François".

11. Se trata de la Compagnie des Iles d'Amerique, ya presentada en 1626 como Compagnie de Saint-Cristophe, de la que Richelieu era el primer accionista y que compartiría las variables vicisitudes del caballero De Poincy hasta 1670, cuando las islas se vendieron a la Compagnie des Indes Occidentales. G.M. Delle Piane (1989). El papel de Richelieu es fundamental: la Compagnie des Iles d'Amerique, refundada por el Cardenal mismo en 1635, le pide ayuda para solucionar con la intervención del Rey los problemas relacionados con el tráfico comercial en las islas. Du Tertre, fiel súbdito francés, le dedica a 
orden, ya que también representa un archivo histórico, donde los numerosos documentos sobre los asentamientos de los franceses en las Antillas proporcionan informaciones acerca de la política de expansión colonial de las principales monarquías absolutas de la edad moderna. Por ejemplo, merece la pena destacar la gran cantidad de informaciones sobre la presencia en las Antillas de la orden de San Juan (más conocida como la orden de Malta), atestiguada por el autor, que se presenta como informador de primera mano, puesto que la fuente conocida hasta la fecha se encontraba en el documento de $1700 \mathrm{de}$ fr. Bartolomeo del Pozzo ${ }^{12}$.

También es una historia de la naturaleza y una historia del hombre: historia general, porque la obra de Du Tertre describe la historia política de los asentamientos con rigor científico, añadiendo testimonios de documentos importantes; describe el aspecto geográfico de las Islas, presenta su flora y fauna con observaciones escrupulosas. Sin embargo, las páginas que más llaman la atención son las dedicadas a los llamados sauvages, en las que se dibuja una embrionaria "antropología del nativo". Por supuesto, no retrata a los habitantes de las Antillas "si polis que le sieur de Rochefort les a fait, en quelques endroit de son livre"13, aunque tampoco ofrece una descripción fiel y objetiva que contraponga la observación y la experiencia a los varios prejuicios de la tradición. Du Tertre refuta así el mito de la inaccesibilidad de la zona tórrida, critica la equiparación del salvaje con el bárbaro y describe más bien sus calidades y características antropológicas:

Richelieu muchos títulos honoríficos: "Cardinal, Conseiller du Roy en ses conseils, Chef, Grand Maitre et Sur-Intendant du Commerce de France". Y también "Pair de France, Commandeur de l'Ordre du Saint Esprit, Gouverneur et Lieutenant General pour sa Majesté en Bretagne et Grand Maitre, Chef et Sur-Intendant General de la Navigation et Commerce de ce Royoume". Tampoco duda en citar una de las "lettres patentes de sa Majesté", en la que Luis XIV recuerda "notre tres cher et aimé cousin le Cardinal Duc de Richelieu, Paire, Grand Maitre, Chef et Sur-Intendant General de la Navigation et Commerce de France". Por otra parte, Du Tertre, dominico y galicano diligente, recuerda que el cardenal Richelieu había inaugurado la primera misión de los religiosos dominicanos "reformados" a la isla de Guadalupe: entre otros, menciona al padre Pierre Pellican, doctor de la Sorbona; el padre Raymond Breton, bachiller de la misma facoltà; los padres Nicolas Brunchy y Pierre Gryphon; e incluso el mismo Du Tertre. Según Du Tertre se trata de una extraordinaria operación política: en su relación con los dominicos Richelieu siempre hace referencia al Breve de Urbano VIII que, al conceder poderes especiales a los misioneros religiosos, de hecho autoriza implícitamente a la monarquía francesa a administrar y gobernar aquellas tierras.

12. B. Del Pozzo (1975); A. Monti della Corte (1969).

13. J.B. Du Tertre (1667-1671), T. II, 355. 
De meme, à ce seul mot de Sauvage, la plupart du monde se figure dans leurs esprits une sorte d'hommes barbares, cruels, inhumains, sans raison, contrefaits, grands comme des geants, velus comme des ours: enfin, plutot des monstres que des hommes raisonnables; quoi q'un verité nos Sauvages ne soient Sauvages que de nom, ainsi que les plantes et les fruicts que la nature produit sans aucune culture dans les forests et dans les deserts, lesquelles quoi que nous les appelions Sauvages, possedent pourtant les vraies vertus et les proprietez dans leur force et dans leur entière vigueur, que bien souvent nous corrompons par nos artifices, et alterons beaucoup, lors que nous les plantons dans nos jardins.

Du Tertre lee a Montaigne: Nos Sauvages ne sont Sauvages que de nom, repite con él. Sauvages que de nom, fuertes y vigorosos, cuya supuesta corrupción depende en gran parte de la corrupción con la que los europeos pervierten sus buenas disposiciones. La influencia de la lectura de Montaigne ${ }^{14}$ es evidente, no sólo en la inversión de valores ratificada por Du Tertre entre la corrupción de la civilización y la simplicidad original de los salvajes, sino también, y sobre todo, en el claro relativismo de los valores y en el nominalismo que introduce a través del tema escéptico del uso, fuente de normas transitorias y de valores adecuados para las diferentes situaciones. Para concluir, vuelve con Montaigne sobre el tema clásico de la contraposición entre los abusos de la razón y la grandiosidad y la potencia de la naturaleza: “ce n'est pas raison que l'art gaigne le point d'honneur sur nostre grande et puissante mère nature". Simplicidad e ingenuidad natural, igualdad social, deseos conmensurados con las necesidades: el hombre natural de Rousseau no estaría muy lejos del sauvage de Du Tertre. El estado natural de los salvajes caribeños es la situación feliz de una humanidad simple y satisfecha, que vive en la belleza y en la salud de una condición ancestral.

Los habitantes de las Antillas tienen un físico fuerte y se distinguen por la tez aceitunada que, escribe el atento observador Du Tertre, llega a teñir ligeramente la parte blanca de los ojos, y también son dotados desde el punto de

14. Sergio Landucci, al tratar la relación entre los filosófos y las crónicas coloniales en su célebre trabajo I filosofi e i selvaggi: 1580-1780, Bari, 1972, insiste en la fuerte influencia que los Ensayos de Montaigne, especialmente el "sobre los caníbales", habrían tenido sobre Du Tertre. El joven Rousseau, lector de Du Tertre, llegaría a las reflexiones sobre el estado de naturaleza de los salvajes de América y quizás incluso a la misma teoría del "buen salvaje" formulada en el Discours sur l'origine et les fondements de l'inégalité, en Oeuvres complétes, vol. III, París, 1964. Según Michèle Duchet (1971, vol. II, 3-36) gracias a sus reflexiones antropológicas -desde las amplias notas Des sauvages en general a las Sur l'origine des sauvages, sobre sus hábitos y sus costumbres, hasta las observaciones sobre la religión de los salvajes y los capítulos sobre los esclavos- Du Tertre incluso podría considerarse uno de los mayores intérpretes del fenómeno del marronage. 
vista intelectual, al ser indudablemente más ignorantes, pero también menos corruptos por un ejercicio malicioso de la razón:

Ils ont le raisonnement bon, et l'esprit autant subtil que le peuvent avoir des personnes, qui n'ont aucune teinture des lettres, et qui n'ont jamais eté subtilisez et polis par les sciences humaines, qui bien souvent en nous subtilisant l'esprit, nous le remplissent de malice: et je puis dire avec verité, que si nos Sauvages sont plus ignorans que nous, qu'ils ne scavent presque de malice que ce que nos François leur en apprennent.

Con tonos dignos de Bernardin de Saint Pierre, Du Tertre incluso entra en la psicología de los salvajes: "Ils sont grands réveurs, et portent sur leurs visages une physionomie triste et melancolique. Ils passent des demy-journées entières assis sur la pointe d'un roc, ou sur la rive, les yeux fichez en terre au dans la mer, sans dire un seul mot"15.

En la literatura de la época, la melancolía de los salvajes es un motivo recurrente que se ha intentado explicar con diferentes hipótesis: desde el sufrimiento provocado por la ocupación colonial, a la torpeza de la mente, a un residuo de sentimiento que permanecería a pesar de la práctica de la antropofagia ritual. Según Du Tertre la mirada triste del salvaje es al mismo tiempo una cita literaria y una observación antropológica: la escena del largo silencio de estos soñadores sentados a orillas del mar contemplando las bellezas de la creación con los ojos fijos y pensativos es una imagen de tristeza y melancolía para el observador occidental que está acostumbrado a los gestos y actitudes de los "nacidos bajo el signo de Saturno". Pero ¿los salvajes silenciosos a orillas del mar realmente pueden haber "nacido bajo el signo de Saturno"?

Por lo tanto, aunque el dominico sigue las huellas de los grandes exploradores y narradores, sin embargo se distingue por su rigor metodológico y su enfoque hacia la observación científica "verídica y sincera" de hechos y cosas. En definitiva, Du Tertre es fiel a los imperativos del conocimiento objetivo, así que no es apologeta, ni detractor, ni moralista: está lejos de la polémica y la denuncia política al estilo de Las Casas ${ }^{16}$, y tampoco se queda en la crónica típica de los religiosos de la primera conquista sobre la condena de las costumbres y las actitudes que ya se habían convertido en tópicos, como el Inca Garcilaso de la Vega, Lopez de Gomara, Cieza de Leóon, Oviedo, Acosta, Cortés, Ber-

16. B. DE LAS CASAS (1958). 
nardo Díaz del Castillo entre otros ${ }^{17}$. El dominico además se sitúa en el centro de ese grupo de exploradores religiosos que con sus relatos enriquecerán las páginas de la literatura de viajes de la época: Cartier, Coreal, La Popelinière, Labat, Abbeville, Dampier, Evreux, Frezier, de Lery, Palafox ${ }^{18}$. En definitiva, $\mathrm{Du}$ Tertre es, ante todo, un historiador: por supuesto misionero, pero sobre todo explorador metódico. En esto estriba su modernidad. El capítulo sobre la religión de los sauvages no es un anatema, sino una página fundamental de la antropología de las religiones. La observación atenta del animismo y la descripción de la ritualidad idolátrica de los nativos de las Antillas no son tan distantes de las perspectivas de los fundadores de la moderna antropología, desde Durkheim y su investigación de las diferentes formas de la religiosidad natural a Lévi-Strauss y su teoría de la necesidad de lo sagrado ${ }^{19}$.

$\mathrm{Du}$ Tertre se mantiene fiel a los compromisos epistemológicos de una investigación imparcial de la verdad histórica y constante en la profesión de aquella "veracidad y sinceridad" que había defendido desde el principio de su obra, en el tratado De la Religion des Sauvages ${ }^{20}$, y sigue siendo el historien metódico y atento de los relatos sobre la flora, la fauna y los movimientos políticos de las islas que había descrito cuidadosamente en la primera parte de su obra. Por supuesto, no falta el marco conceptual y dogmático donde él, dominicano riguroso y misionero apasionado, sitúa la problemática muy deli-

17. G. De la Vega (1974); L. De Gómara (1987); H. Cortés (1945) y (1982); B. Díaz deL Castillo (1877).

18. C. D'Abbeville (1963); F. Coreal (1722); J.M. Crozet (1783); W. Dampier (1698); Y. D'Evreux (1864); M. Frezier (1732); J. DE Lery (1880); J. De Palafox (1893).

19. E. Durkheim (2005); C. LÉVI-STrauss (1966), (1962) y (1984).

20. Jacques Du Tertre, nombre religioso Jean Baptiste, nace en Calais en 1610, en un siglo de descubrimientos geográficos, de reflexiones sobre el método y de programas de ciencia, en el que es espectador $\mathrm{y}$, al mismo tiempo, protagonista de acontecimientos históricos ricos de conflictos políticos y caracterizados por enfrentamientos entre fuertes identidades religiosas en la Francia del Antiguo Régimen. Es un personaje complejo, casi emblemático de la cultura del Grand Siècle, militar y religioso, explorador y misionero. Al principio se enrola en la marina holandesa, visita Groenlandia y posteriormente entra en la armada francesa. Ingresa en la orden de Predicadores a los 25 años en 1635, y en calidad de religioso se instala varias veces en las Antillas - en la isla de Guadalupe de 1640 a 1642, en la Martinica en 1647 y de 1656 a 1657-, que observa y analiza con la actitud enciclopédica del naturalista, del geógrafo, del historiador, del etnólogo, del antropólogo y del analista. Las describe en la Histoire générale des isles de S. Christophe, de la Guadeloupe, de la Martinique et autres dans l'Amerique, où l'on verra l'establissement des colonies françaises dans ces isles, publicada en 1654, durante el período que pasó en Francia, de 1647 a 1655. Du Tertre sucesivamente volverá a las Antillas pero, debido a numerosas tribulaciones, volverá definitivamente a Francia y morirá en París en 1687. I. Guet-Michaud (1893), 394; P. Fournier (1932), 35; E. Bourgeois y A. Louis (19131935), 67-68. S. Landucci S. (1972) J. J. Rousseau (1964); Duchet M. (1971), vol. II, 3-36. 
cada de la religión primitiva: la contraposición entre luz del cristiano y tinieblas del infiel que podía representar un fundamento para todo el discurso; la evocación de las virtudes teologales con las que san Pablo definía ese marco; o bien aquella distinción entre religión y superstición con la que se establecían categorías dentro de ese marco:

C'est une chose tout à fait déplorable, de voir naistre ces pauvres Sauvages dans l'infidelité, passer toute leur vie dans les tenebres, et comme dit Saint Paul, filij irae Deo in hoc mundo, apres avoir vécu sans aucune connoissance de Dieu, mourir sans esperance de salut: car nous aurons plustost fait de dire qu'ils n'ont point du tout de Religion, que de faire passer toutes leurs badineries, superstitions, ou plustost sacrileges, dont ils honorent tous les demons qui les seduisent, pour un culte de quelque divinitéé ${ }^{1}$.

Sin embargo, en el capítulo III de esta segunda parte, Du Tertre, a diferencia de Rochefort ${ }^{22}$-al que no duda en criticar una vez más para hacer hincapié en la importancia de la observación y la experiencia directa- aparece dispuesto a reconocer la existencia de una forma de religiosidad natural que los salvajes poseerían, por lo menos como predisposición. Se trata de la creencia-quelque sentiment, como la define Du Tertre- en la existencia de un Dios creador cuyos atributos, a pesar de lo que afirma Rochefort, aparecen muy cercanos al incipit del Credo. Los atributos de Dios vuelven a ser los mismos: el "sentimiento" de los "salvajes" de un Dios muy poderoso que hizo el Cielo se acerca a la teoría cristiana de la omnipotencia de la creación divina, y es supreme verité, ratificada por la inconmensurabilidad entre Creador y criatura:

21. J.B. DU TERTRE (1967), 364.

22. En lo que atañe a Rochefort, ministro de Rotterdam, tenemos que consultar el Catalogue Général des livres imprimés de la Bibliotèque Nationale, París 1938; en el lema Rochefort (César de), se mencionan numerosas publicaciones que abarcan desde composiciones literarias hasta relatos de viaje: Abrégé des métamorphoses, ou Fictions poétiques réduites en questions pour les curieux de l'histoire profane et l'instruction de la jeunesse, 1685; Dictionnaire générale et curieux contenant les principaux mots et les plus usitez en la langue françoise, leurs définitions, divisions et étymologies, enrichies d'éloquens discours, soutenus de quelques histoires, des passages des Pères de l'église, des autheurs et des poètes les plus anciens et modernes, avec des démonstrations catholiques sour tous les points qui sont contestez entre ceux de l'Eglise romaine et les gens de la religion prétendue réformée, 1685; Histoire naturelle et morale des iles Antilles de l'Amerique avec un vocabulaire caraibe, 1658, en el mismo lema que trata la publicación mencionada, los editores escriben: «cet ouvrage est attribué au P. Jean-Baptiste Du Tertre, le Vocabulaire caraibe pourrait etre du P. Breton»; Relation de l'isle de Tabago ou la Nouvelle Oualcre, l'une des isles Antilles de l'Amerique, 1666. 
Ils ont pourtant quelque sentiment d'un Dieu, plus puissant que tous ceux dont nous allons parler, et ils tombent d'accord avec nous qu'il a fait le Ciel, et qu'il y reside, et bien que le Sieur de Rochefort dise qu'ils y mettent cette distinction, que le Dieu de la France a fait le Ciel de la France, et le Dieu des Isles a fait celuy des Isles : j'en ay veu plusieurs qui estoient de ce sentiment, et accordoient sans distinction cette supreme verité23.

La tendencia a lo verdadero y lo bueno representa la entera estructura doctrinal de la teología moral cristiana, y Du Tertre, dominico riguroso, no olvida la gran lección de la Escolástica ${ }^{24}$ : las inclinaciones naturales son el fundamento de la ley natural, de la que dependen los valores éticos y sobre la que se modelan comportamientos éticos, ya que lo Verdadero y lo Bueno derivan de los atributos de Dios. Tanto los cristianos como los "salvajes" participan de ellos. Sin embargo, es en los nombres divinos donde el Du Tertre comparatista logra destacar también las distinciones entre los cristianos, que pueden experimentar el conocimiento de Dios también como fuerza de elevación moral en virtud de la gracia divina, y los nativos de las islas que, en cambio, están vinculados a un culto utilitarista de las divinidades, que los aparta de aquellos principios embrionarios de religión monoteísta:

Ils avouent mesme qu'il est doué d'une si grande bonté, qu'il ne fait aucune mal à personne : mais au lieu de s'elever par cette connoissance, ils le laissent comme indifferent, ne rendant leur honneur, et ne presentant leurs offrandes qu'à ceux dont ils esperent de l'utilité, et dont ils craignent les malefices ${ }^{25}$.

El Dios que está en los cielos, subraya Du Tertre, es bueno, pero en vez de elevarse a través de esta supreme verité hacia la que permanecen indiferentes, los "salvajes" de las Antillas, esclavos de lo útil, se desvelan en ofrendas a divinidades menores, de las que temen los maleficios. A un comparatista católico como Du Tertre no se le escapa que la distinción fundamental es aquella

23. J.B. DU TERTRE (1667-1671), T. II, 365.

24. S. PINCKAERS (1985), 503: "San Tommaso indica con una sintetica espressione quando parla dell'inclinazione naturale alla verità riguardante Dio, facendo coincidere il desiderio della verità con il desiderio di Dio origine e fine di ogni verità. L'inclinazione naturale alla verità ha perciò una portata universale in morale, come in tutti i campi della conoscenza. Si può dire che essa forma, nell'uomo, il senso stesso dell'universale. Perciò ogni verità, anche la più semplice e umile, possiede come un alone, un'irradiazione di universalità. L'universalità delle leggi morali sarà fondata precisamente sulla loro verità, in conformità con la natura umana che, nella sua intelligenza, è stata creata per la verità".

25. J.B. DU TERTRE (1667-1671), T. II, 365. 
entre la maldad invencible del hombre y la gracia concedida a la criatura de elevarse $-s$ 'élever se usa habitualmente en el lenguaje teológico- desde el estado de pecado original al de hija de Dios que se completa con la obra de Cristo, autor de esta elevación en virtud de su Encarnación.

Sin embargo, una vez más, Du Tertre historien se encarga de detallar los elementos fundamentales del credo religioso de los llamados salvajes, que combinan un monoteísmo genérico con un politeísmo que además se decanta hacia una forma de maniqueísmo plural. En este maniqueísmo plural, las divinidades benéficas o maléficas son sexuadas, se reproducen, son humanas como los hombres, pertenecen a distintos pueblos y entran en contacto con los hombres a través de los mediadores, los Boyez:

Ils croyent communément deux sortes de Dieux, dont les uns sont bons qu'ils appellent Ichéiri, et les autres sont mauvais qu'ils nomment Maboya, ou Mapoya, ils croyent qu'il y a entre eux diversité de sexes, qu'ils multiplient, et qu'il est homme comme eux, qu'ils sont de diverses nations, et que quand ils sont appellez par leurs Boyez, ils amenent quelquefois les enfans des enfans de leurs enfans ${ }^{26}$.

Puesto que son dotados de poderes mágicos, según los indígenas antillanos:

ces esprits ou ces Dieux ont le pouvoir de faire croistre leur magnyocs, qu'ils les peuvent secourir dans leurs maladies, qu'ils les aident dans leurs combats, qu'ils font les Ouragans, qu'ils empoisonnent et font mourir qui bon leur semble. Ils ont parmy eux certains charlatans, que les Sauvages appellent Boyez, et le sieur de Rochefort, pretres, sorciers ou magiciens ; mais puis qu'il dit que ces Boyez n'offrent point de sacrifice, et que c'est le propre des Pretres d'en offrir, il me semble qu'il auroit mieux fait de les nommer Ministres comme luy.

Aquí no puede pasar desapercibido el sentido de la polémica que Du Tertre reaviva con Rochefort, al que le exige corrección léxica para que pueda mantenerse la corrección dogmática: llamar a los Boyez "ministros" y no "curas", según el misionero dominico, es prueba de rigor científico, puesto que la tarea distintiva del "cura" es ofrecer un sacrificio, que para el cristiano es el de la Eucaristía, que lo distingue de los ministros del culto, y que los Boyez de las Antillas no hacen. Además, asociar términos como prêtres, sorciers

\section{Ibidem.}


ou magiciens, como había hecho Rochefort, ¿acaso no delataba un profundo
desprecio hacia la religión católica? Los Boyez podrían considerarse más bien
chamanes, en el sentido que Mircea Eliade les atribuye, aunque el debate to-
davía queda abierto sobre este fenómeno misterioso bajo muchos aspectos ${ }^{27}$.

27. Vid. E. Mircea (1990); C. Lévi-Strauss (1966); K.E. Müller (2001); A. Metraux (1971). La figura del chamán nace en las sociedades primitivas con el objetivo de resolver problemas básicos para la supervivencia comunes a todos los pueblos: salud, reproducción, subsistencia. Según estas sociedades primitivas, eran fundamentalmente los espíritus ultraterrenos los que decidían el destino y lo que ocurría sobre la tierra, por lo tanto los problemas sólo podían ser resueltos por un ser semejante que tuviese la capacidad y los medios para entrar en contacto con ellos y para emprender un "viaje" ultraterreno al mundo de los espíritus, donde podían encontrar la solución de los problemas. El chamán hacía precisamente esto, era un "puente" entre el mundo terreno y el ultraterreno. Según la cultura chamánica, una persona no puede convertirse en chamán por su propia elección o por una simple iniciación, sino que tiene que recibir una "llamada" por parte de los "espíritus", una llamada que es obligatorio aceptar. Después de esta llamada, en algunas culturas, puede haber una iniciación. La llegada de la "llamada" a menudo es dramática para quien la recibe, porque devasta su vida y perjudica seriamente la estabilidad e integridad física y psíquica de la persona, por lo que prescindiría de ella, pero el rechazar, según la tradición chamánica, tendría consecuencias mucho más graves, que incluso podrían llevarla a la locura y a la muerte. En general, en el chamanismo clásico, los chamanes son hombres, pero también existen chamanas, que son más frecuentes en los grupos sedentarios, sobre todo en las sociedades agrarias y campesinas (p. ej. Uzbekos y Tayikos, pero también en el Extremo Oriente y el Sudeste asiático). Su papel, sin embargo, en general es marginal con respecto al de los chamanes hombres porque, según la tradición chamánica, el "viaje" de un chamán de sexo masculino tendría un mayor alcance y un radio de acción mucho más amplio, y su acción sería mucho más potente. Las chamanas -allí donde existen-, en cambio, en general serían más "especializadas" en aquellas curas que requieren conocimientos de herboristería. El chamán, a diferencia de lo que ocurre con el sacerdote o el rey, no deriva de una institución, sino que tiene una base empírica, posee facultades innatas o transmitidas y, a diferencia del brujo-médico, tiene un comportamiento estático: cuando está en trance es un puente entre las energías espirituales y las terrenas, un canal de la voluntad divina y de las fuerzas de la naturaleza, que pone a disposición de la humanidad a través del amor y la comprensión. Durante el éxtasis se apodera de él una fuerza (que puede concebirse desde el punto de vista dinámico como impersonal, o bien desde el punto de vista animista como espíritu o demonio): con esta ayuda el chamán influye en la vida de sus compañeros. El vínculo entre el chamán y el poder que lo invade es muy estrecho, él pierde su personalidad y momentáneamente se convierte en el "otro". Chamanes de la América septentrional y de Groenlandia llevan máscaras precisamente para representar este aspecto. No siempre todo esto es percibido como un don sino que también es temido como la muerte, por su potencia. Algunas culturas chamánicas vinculan sus orígenes con las mujeres, como por ejemplo el chamanismo que actúa a través del águila, o también en Chile, donde las chamanas Mapuche desde hace 25000 años practican sanaciones en relación con la luna. En los Ciukci del Asia septentrional o los Daiaki de las costas de Malasia, el chamán a veces incluso se "convierte" en mujer y en cuanto tal se casa. Los chamanes son protectores de la mitología de los recogedores-cazadores (cuya vida se funda en la economía de subsistencia, en la predicción y en la relación directa con la naturaleza) y juegan un papel esencial en la evolución de las sociedades a las que pertenecen. Las reglas fundamentales de la práctica chamánica son el respeto de la individualidad y de la libertad de cada individuo; para el chamán está prohibido hacerse daño a sí mismo y hacerles daño a los demás, faltarle de respeto a la Madre Tierra y a cualquier expresión de vida, así como recibir retribuciones monetarias. Un rasgo signifi- 
cativo de la "cura" según la creencia chamánica es el hecho de que la sanación es tanto física como psíquica. Una parte de la psiquiatría moderna atribuye las posibles sanaciones a hipnosis o autohipnotismo, o incluso a hipnotismo colectivo. Los instrumentos musicales, por ejemplo, con el estruendo violento que a menudo acompaña estas prácticas, "arrancan" al sanador y al paciente de su existencia habitual, con una función terapéutica. El chamanismo, en su origen vinculado a las culturas de cazadores-recogedores, parece estar presente en casi todo el planeta, desde Australia hasta las Américas, con algunos rasgos compartidos por todos los pueblos interesados. Este fenómeno, en cambio, no se encuentra en el continente africano, ni en las sociedades de cultivadores de Melanesia y Nueva Guinea, ni tampoco en las áreas de las grandes civilizaciones de la antigüedad, como la china, las grandes civilizaciones del Mediterráneo, las mesoamericanas y andinas. Es posible que existiese en los orígenes de las grandes civilizaciones, y que posteriormente se haya suprimido. En África, en cambio, donde se encuentra otra figura, la del brujo, no hay ningún testimonio de chamanismo, y ni siquiera las más antiguas pinturas rupestres ofrecen indicaciones a este respecto (aunque de vez en cuando se proponen hipótesis opuestas). Sepulturas en cuevas del norte de Irak, en Shanidar, que según las dataciones se remontan a 150000 años, y también petroglifos de Norteamérica de hace 7000 años, hacen referencia a ritos chamánicos. El chamanismo, en cambio, aparece especialmente arraigado en Asia, sobre todo en Siberia, donde no hubo, o apenas hubo, superposición de otras culturas; el chamanismo siberiano, por lo tanto, es considerado por los estudiosos como el clásico, el más puro. Sabemos que el Estrecho de Bering, que a menudo está congelado, era el itinerario seguido por los cazadores del Paleolítico (homo sapiens sapiens) para penetrar en el continente americano; desde el Sudeste de Asia penetraron hasta Australia 53000 años antes de nuestra era, por lo que los actuales aborígenes son sus directos descendientes. Prácticas chamánicas se encuentran casi en todas partes: en los Ciukci, los Inuit, los Yupik, los Samoiedos, los Cumanos, los Tártaros y los Mongoles, los Buriatos, los Daigatos del Borneo, en Oceanía, en el Sudeste Asiático, en la India, en el Tíbet, en Japón y en el continente americano, pero también se dan fomas más "refinadas", como por ejemplo en los Yoag Indios, o los Berserkr germánicos que se enfurecen en las batallas, o incluso los héroes poseídos por el espíritu de Jahvé en el Antiguo Testamento (Gedeón y Saúl, que luego se incluye entre los profetas). Algunos ritos chamánicos también fueron practicados en China a lo largo de la historia: su presencia está confirmada por las fuentes históricas Han, según las que numerosos chamanes que vivían en el territorio chino en el siglo III a.C. eran invitados por los emperadores para la construcción de altares y templos en la capital. A pesar de la hostilidad de los funcionarios de la corte, estos chamanes mantuvieron un papel importante durante más de un milenio hasta la promulgación de un edicto de 1023 en el que se ordenó que los chamanes volvieran a sus provincias de origen y que se derrocaran los altares; en una época en la que el estado quedaba casi completamente "confucianizado", el chamanismo fue abolido por la corte, pero siguió siendo practicado a nivel popular hasta hoy en día, aunque con una difusión mucho menor. Los indígenas de Nueva Guinea, bajo el efecto de algunas drogas, estaban convencidos de que podían entrar en contacto con los familiares difuntos: el problema que surgía era que un muerto que volvía entre los vivos cambiaba su carácter, así que si era bueno podía volverse malo y al revés; este cambio estaba en la origen de los ritos funerarios, que tenían el objetivo de prevenirlo o favorecerlo. Los Roro de Nueva Guinea ponían en escena una ceremonia extraña para reunir en el pueblo a los espíritus de los muertos, que consideraban como sus aliados. Se han propuesto diferentes teorías para explicar la difusión casi global del chamanismo. A continuación presentamos las principales. 1) La llamada teoría difusionista, según la que el fenómeno pudo haberse originado en un determinado pueblo para luego difundirse de un pueblo a otro y de un lugar a otro. 2) La teoría de la derivación de una fuente común, según la que el fenómeno habría llegado a cada pueblo a partir de una misma fuente. 3) La llamada teoría estructuralista, según la que el fenómeno podría haber surgido contemporáneamente en diferentes lugares y en distintos pueblos porque es 
una "casta sacerdotal" consagrada desde la juventud al ministerio ritual que preveía una serie de prácticas ascéticas de ayunos y autopuniciones, cuyo fin era llegar a convertirse en "una especie de medio de expresión, un medio para la conexión entre los hombres y lo divino", según la definición de Cassirer ${ }^{28}$.

Sin embargo, el panteón de los "salvajes" isleños se complica aún más con la presencia evocada por Du Tertre de divinidades protectoras u hostiles estrictamente individuales, una especie de "ángel de la guarda" que la gran divinidad concede al individuo gracias a la intercesión ritual del mediador:

(...) ce Dieu ou ce Diable, luy en donne un, qui paroist en forme d'homme; et si c'est une femme, il luy donne une sesse qui paroist aussi en forme de femme; et l'on ne dit pas parmy eux que ce soient les Dieux des Sauvages, mais le Dieu d'un tel, ou la Déesse d'une telle ${ }^{29}$.

¿Posesión? ¿Trance como en el episodio relatado por el Padre Raymond, otro gran conocedor de la cultura caribeña? ¿O experiencia esotérica de una mujer arrebatada por un sueño de inmortalidad?

Il adjoustoit que son Dieu estoit un jour entré dans le corps d'une femme, qu'il l'avoit porté plusieurs fois par dessous le Soleil, sans qu'elle fut esblouye de ses rayons: que là elle avoit veu plusieurs belles terres découpées par des rochers, d'où rejallissoient une infinité de tres belles sources d'eau viue, et qu'il luy promettoit qu'apres sa mort, elle viuroit en ces lieux avec luy ${ }^{30}$.

innato en la estructura mental humana. Según la antropología oficial, los rasgos fundamentales que caracterizan al chamán, que son comunes a todos los lugares donde se había difundido la creencia chamánica y son casi idénticos desde Australia hasta las Américas y hasta Asia, son: 1) La llamada chamánica. El chamán, antes de convertirse en tal, afirma que recibió una "llamada" por parte de los "espíritus", a la que tuvo que contestar afirmativamente. 2) El viaje chamánico. Un "viaje" mental, onírico al "mundo de los espíritus", que el chamán emprende en el momento de su investidura y también posteriormente, con diferentes modalidades (a veces incluso con alucinógenos) cada vez que actúa para resolver problemas suyos, de la comunidad o de los individuos. Las fases características del "viaje" son: a) trance (estado psíquico alterado que en algunos casos se alcanza con el uso de alucinógenos y que permanece a lo largo de todo el "viaje"), b) metamorfosis, el chamán se convierte (durante el viaje, es decir en el sueño) en el animal que lo protege y que le otorga su poder. c) lucha (durante el viaje lucha contra los espíritus y otros chamanes). d) Regreso (el chamán "vuelve" del "viaje" con la solución al problema). 3) Anargirismo, es decir la prohibición para el chamán de recibir remuneraciones monetarias (al infringirla perdería el poder chamánico).

28. E. CASSIRER (1999), 313.

29. J.B. DU TERTRE (1667-1671), T. II, 366.

30. Ibidem. 


\section{El fenómeno también está relacionado con la medicina y la terapia:}

(...) le Boyé et le Dieu pretendu, s'approchent du malate, tastent, pressent, et manient plusieurs fois la partie affligée, soustant toujours dessous; et en tirent quelquefois, ou font semblant d'en tirer des épines de Palmiste longues comme les doigts, de petits os, des dents de serpent et des éclats de bois, persuadent au malate que c'est ce qui luy causoit de la douleur. Souvent ils succent la partie malade, et sortent incontinent dela Case pour vomir, à ce qui ils disent, le venin : ainsi le pauvre malade demeure guery plus par imagination qu'en effet, et plus enchanté que desabusé. (...) Quand le malade est guery, il fait un festin ou l'Ichéiry, où le Dieu pretendu, et le Boyé ne manquent pas de se trouver ${ }^{31}$.

La narración sigue con los relatos de muchos episodios rituales en los que una parte de la comunidad se reúne con los ministros para pedir ayuda a la divinidad en el tratamiento de enfermedades y en la liberación de los maleficios. Para ser exhaustivo, Du Tertre menciona también la relación ancestral con los antepasados, en particular con los huesos de los muertos a través de oráculos, y habla de los fetiches y de los maleficios en los que se empleaban. En definitiva, Du Tertre parece coincidir con Durkheim en que el fenómeno religioso de estas realidades primitivas es fundamentalmente un hecho social ${ }^{32}$.

El capítulo sobre la religión se cierra con la tratación del discurso sobre el alma y la inmortalidad, en las que los isleños creen firmemente, según escribía $\mathrm{Du}$ Tertre, pero que conciben a través de formas sensibles, y experimentan como un vitalismo espontáneo ${ }^{33}$, por lo que aparecen cercanos en la creencia, pero a la vez muy distantes de la concepción cristiana en las formas ${ }^{34}$ :

31. J.B. DU TERTRE (1667-1671), T. II, 368.

32. Durkheim $(2005,59)$ escribe: "Di un sistema religioso diciamo che è il primitivo che possiamo osservare quando soddisfa le due condizioni seguenti: in primo luogo, deve risultare presente in società la cui organizzazione non sia superata da nessun'altra in fatto di semplicità; in secondo luogo, esso deve poter essere spiegato senza ricorrere ad alcun elemento tratto da una religione anteriore. La religione è cosa eminentemente sociale. Le rappresentazioni religiose sono delle rappresentazioni collettive che esprimono realtà collettive; i riti costituiscono dei modi di agire che sorgono in mezzo a questi gruppi e sono destinati a suscitare, a mantenere o a riprodurre certi stati mentali di questi gruppi".

33. Sobre la concepción del alma "mítica", Cassirer (1999, 223-224) escribe: "Come la vita, in quanto tutto è indiviso, è immanente alla totalità del corpo, così essa è presente in ogni sua singola parte. Non solo determinati organi importanti per la vita, quali il cuore, ma ogni qualsiasi parte costitutiva del corpo, anche quando non si trova più in alcun nesso organico con la totalità di questo, può ancora essere pensata come portatrice della vita ad essa immanente. (...) La morte non è mai distruzione dell'esistenza, ma solo passaggio ad un'altra forma d'esistenza; e anche questa, nelle fasi fondamentali e primitive del pensiero mitico può essere pensata soltanto in una concretezza del tutto sensibile".

34. Por otra parte el magisterio cristiano siempre ha considerado el corazón como sede del alma y de Descartes en adelante esta referencia será revisada y debatida desde una pers- 
Ils croyent l'immortalité de l'ame, mais ils tiennent que chaque persone en a trois: une au coeur, une à la tete, et l'autre au bras. Celle du cour, qui se manifeste par ses battemens : va, disent-ils, droit au Ciel apres la mort, pour y estre bien-heureuse : celles du bras et de la tete qui se manifestent par le battement du poulx, et par le mouvement des arteres, deviennent Maboyas, c'est à dire, esprits malins, ausquels ils imputent tout ce qui leur arrive de sinistre et de funeste ${ }^{35}$.

Inclinaciones naturales, por supuesto; homo capax religionis, evidentemente; sentiment de los "salvajes": Du Tertre consigue entrelazar Aristóteles, San Tomás y los nativos de las Antillas. Por supuesto, la literatura antropológica moderna ${ }^{36}$ no podrá admitir tan fácilmente esta asimilación que ya Dur-

pectiva esencialmente filosófica. "Mi sono convinto" escribía Descartes "che l'anima non può avere in tutto il corpo altra localizzazione all'infuori di questa ghiandola, in cui esercita immediatamente le sue funzioni, perché ho osservato che tutte le altre parti del nostro cervello sono doppie, a quel modo stesso che abbiamo due occhi, due mani, due orecchi, come, infine, sono doppi tutti gli organi dei nostri sensi esterni. Ora, poiché abbiamo d'una cosa, in un certo momento, un solo e semplice pensiero, bisogna di necessità che ci sia qualche luogo in cui le due immagini provenienti dai due occhi, o le altre duplici impressioni provenienti dallo stesso oggetto attraverso gli organi duplici degli altri sensi, si possano unificare prima di giungere all'anima, in modo che non le siano rappresentati due oggetti invece di uno: e si può agevolmente concepire che queste immagini, o altre impressioni, si riuniscano in questa ghiandola per mezzo degli spiriti che riempiono le cavità del cervello, non c'è infatti nessun altro luogo del corpo dove esse possano esser così riunite, se la riunione non è avvenuta in questa ghiandola. L'opinione poi di quelli che credono che l'anima riceva le sue passioni dal cuore, non è da prendersi nella minima considerazione, essendo fondata esclusivamente sul fatto che le passioni fanno avvertire nel cuore qualche alterazione; è facile notare che questa alterazione è avvertita come se fosse nel cuore solo per l'azione di un piccolo nervo che discende dal cervello verso di esso, così come un dolore è localizzato nel piede per via dei nervi del piede, e gli astri sono localizzato nel cielo per la loro luce e per i nervi ottici; di modo ché non è più necessario che la nostra anima eserciti immediatamente le sue funzioni nel cuore per sentire in esso le passioni, di quel che non sia necessario che essa sia nel cielo per vedere in questo gli astri”. CARTESIO (1992), 30-35.

35. J.B. DU TERTRE (1667-1671), T. II, 372.

36. G. Filoràmo (1997) "L'Essere Supremo è identificato con l'antenato primordiale, ad esempio presso i Pano della montagna peruviano-boliviana, i Tupinambà (Tamoi, che è anche dio creatore e fu molto importante nella genesi dei millenarismi), i Botocudo (Yekankren:vecchio uomo), i Mundurucù (Karusakaibe: padre), i Witoto (Momo, padre dell'umanità), gli Shipibo che ancora nel 1928 erano indicati dal viaggiatore tedesco G. Tessmann come uomini senza dio. Salvo poche eccezioni, l'Essere Supremo -qualunque sia il suo spessore divino e la sua presenza nel culto, creatore o trasformatore- non è quasi mai l'unico autore e responsabile del cosmo: al suo fianco si può trovare una moglie (Apapocuva Guaranì), un figlio unico (Taìno), oppure una coppia gemellare (Calina, Apapocuva), un fratello, gemello o meno (Caribi del medio Orinoco), un demiurgo, oppure fenomeni naturali come Tuono, Fulmine, Lampo, oppure animali reali o mitici (Witoto)". Vid. también: R. PetTazzoni (1957); E. Durkheim (2005); E. CAssirer (1999); M. Eliade (1978) (2005); D. Bisnauth (1996); C. Castaneda (1995); F.A. Lana y L.G. Lana (1986); M. Perrin (1986); E. Schaden (1988), 283-331; C. LÉvi-Strauss (1962) (1984); O. Zerries (1966); V. Lanternari (1960); A. MetrauX (1931), 61-91; J. ShapIRO (1987), 126-139; V. DE QueIros (1973), 43-61. 
kheim pondrá en tela de juicio ${ }^{37}$ y sobre la que también volverá Pettazzoni ${ }^{38}$. Pero es cierto que tanto sobre la existencia de Dios y sobre sus atributos como sobre la inmortalidad del alma Du Tertre lleva a cabo una especie de normalización de los nativos de las Antillas a la fe cristiana, por lo menos en lo que atañe el planteamiento filosófico-teológico fundamental. Sin embargo, tampoco pasa por alto las numerosas diferencias entre una religión de la luz y aquella "ignorancia invencible" que en cambio caracteriza la religión de los indígenas de las Antillas, encerrados en su búsqueda de lo útil y del sentido en sus creencias.

Bergson hablaba de impressions fuyantes ${ }^{39}$, las únicas que revelan una realidad, porque están más cerca de la verdad. En nuestra opinión Du Tertre recoge precisamente estas impresiones, liberándose de muchas pautas interpretativas de su siglo para ser un buen historien y presentar la Histoire generale des Antilles.

De todas formas, Du Tertre evita aquellos elementos de la tópica moralista de su época que consideraba los usos y costumbres de los nativos como la expresión de la depravación del hombre natural: no hizo mención de la supuesta sodomía y de la antropofagia del "salvaje" que habían inspirado los relatos de los numerosos exploradores, ni de las supuestas prácticas perversas de los pueblos nativos. Sólo ofrece una mirada compasiva sobre los sufrimientos de los esclavos de color obligados a condiciones inhumanas, y también formula una condena lúcida y tajante de la esclavitud.

37. E. Durkheim (2005), 9: "La seule considération des formes religieuses qui nous sont les plus familières a fait croire pendant longtemps que la notion de Dieu était caractéristique de tout ce qui est religieux. Or, la religion que nous étudions plus loin est, en grande partie, étrangère à toute idée de divinité ; les forces auxquelles s'adressent les rites y sont très différentes de celles qui tiennent la première place dans nos religions modernes".

38. R. Pettazzoni (1957), 17: "Io ritengo" escribe el célebre profesor de Historia de las Religiones "che la teoria del monoteismo primordiale è viziata in limine da un equivoco. L'equivoco consiste nel chiamare monoteismo ciò che è semplicemente la nozione di essere supremo. Con ciò si trasferisce in blocco alla più arcaica civiltà religiosa l'idea di Dio propria della nostra civiltà occidentale, quell'idea di Dio che dall'Antico Testamento è passata nel Nuovo ed è poi stata successivamente elaborata in seno al Cristianesimo (...). Ciò che i teorici del monoteismo primordiale pongono come forma prima (la più antica conoscibile) della religione, non è il monoteismo quale ci appare in forma concreta nelle grandi religioni monoteistiche storiche, bensì un'idea monoteistica in astratto con gli attributi ad essa assegnati dalla speculazione teologica e del pensiero filosofico tradizionale dell'Occidente. L'essere supremo dei popoli primitivi soltanto approssimativamente corrisponde a questo ideale monoteistico".

39. Vid.H. Bergson (1970). 
C'est veritablement en la personne des Négres, que nous déplorons les miseres effroyables qui sont attachées à la servitude: les Brasiliens et les Arouagues que nos habitans achetent pour les servir, sont esclaves à la verité, puis qu'ils ont perdu leur liberté, et que leurs maitres en peuvent disposer comme il leur plait, mais ils ne souffrent presque rien de la fatigue et des travaux de cette facheuse condition, les Nègres seuls en portent toute la peine: et comme si la noirceur de leur corps etoit le caractere de leur infortune, on les traite en esclaves, on les nourrit comme on veut, on les pousse au travail comme des betes, et l'on en tire de gré ou de force jusqu'à leur mort, toute le service dont ils sont capables.

Du Tertre desvela con extrema claridad los sórdidos motivos de la discriminación y de la infelicidad de estos Nègres: la noirceur de leur corps. Ninguna razón justifica aquellas crueldades. La realidad que tiene delante es absurda: puesto que se funda sobre la futilidad de un rasgo tan extrínseco como el color de la piel, la trata de los esclavos lleva al hombre a un tal estado de degradación que se borra toda calidad humana en la víctima. Esta queda así reducida a una bestia que se llevará con frialdad a la muerte, como hace el verdugo, cínico comerciante de carne humana. Y aquí el historiador de las Antillas se convierte en juez de la Europa negrera. La trata es la compraventa de personas; desde hace siglos la llevan de la misma manera comerciantes de determinadas nacionalidades -franceses, ingleses, holandeses, portugueses y españoles- que cuando llegan a las costas del continente africano cargan sus barcos de pobres infelices, una mercadería que vale poco más de unos trozos de metal.

Les Nègres sont tous originaires d'Afrique, tirez des cotes de Guynée, d'Angole, de Senega, ou du Capverd. Les Marchands François, Espagnols, Anglois, Poutgais et Holandois, les y vont traiter pour d'autres marchandises. Quand un Navire arrive à ces cotes, le Marchand du vaisseau s'adresse au Roytelet, ou au Governeur de la Province où il aborde, et ceux-là leur vendent ces pauvres miserables, hommes, femmes, et enfans de tout age, pour des Barres de fer, pour des meulles, pour des petites pieces d'argent, pour de l'eau de vie, pour de la Toile, et pour d'autres denrées dont ils ont le plus besoin en ce pais.

Du Tertre devuelve a ces pauvres miserables dignidad humana. Su Histoire hablará de los habitantes de las islas: de sus costumbres, de su vida, de sus usos. Y de su deseo de libertad "qui est naturel à tous les hommes". 


\section{BIBLIOGRAFÍA}

Bergson, Henri (1970), Les deux sources de la morale et de la religion, in Euvres, París.

Bisnauth, Dale (1996), A History of Religions in the Caribbean, Asmara.

Bourgeois, Emile y Louis, André (1913-1935), Sources de l'histoire de France, XVII s., París.

CARTESIO, Renato (1992), Le passioni dell 'anima, I, Turín.

CASSIRER, Ernst (1999), Filosofia delle forme simboliche. 2, Milán.

CASTANEDA, Carlos (1995), A scuola dallo stregone. Una via yaqui alla conoscenza, Roma.

Coreal, François (1722), Voyages de François Coreal aux Indes occidentales, contenant ce qu'il a vu de plus remarquable pendant son séjour depuis 1666 jusqu'en 1697, traduit de l'espagnol avec une relation de la Guiane de Walter Raleigh et le Voyage de Narborough à la Mer du Sud par le Détroit de Magellan, traduits de l'anglois, Amsterdam

CoRTÉs, Hernán (1945), Cartas de relación de la conquista de Méjico, Buenos Aires.

- (1982), La conquête du Mexique, D. CharnaY (trad.), con introducción, notas y cartas de Bernard Grunberg, París.

Crozet, Julien Marie (1783), Nouveau voyage à la Mer du Sud, commencé sous les ordres de M. Marion [...] et achevé [...] sous ceux de M. le Chevalier Duclesmaur [...] Relation [...] rédigéé d'après les plans et journaux de M. Crozet [...], París.

D’Abbeville, Claude (1963), Histoire de la Mission des Pères Capucins en l'isle de Maragnan et terres circonvoisines, reproducción anastática por Alfred Métraux y Jacques Lafaye, Graz.

D'Evreux, Yves (1864), Suitte de l'Histoire des choses plus mémorables advenues en Maragnam ès années 1613 et 1614, Leipzig-París.

DAMPIER, William (1698), Nouveau voyage autour du monde, Amsterdam.

De La Vega, Garcilaso (1974), Obras completas con comentario, Elías L. RIVERS (ed. crít.), Madrid.

De Las CaSas, Bartolomé (1958), Brevíssima relaciòn de la destruyción de las Indias, en Obras escogidas, vol. V, Madrid.

De LerY, Jean (1880), Histoire d'un voyage fait en la terre du Brésil, Paris.

Delle Piane, Gian Marino "Il dominio coloniale dell'Ordine di Malta nei Caraibi”, en La sfinge Americana e gli italiani. Atti, Genova, 1989, 135-179.

De Palafox, Juan (1893), Virtudes del Indio, Madrid. 
De Queiros, V. (1973), “Cargo Cult na Amazonia sobre o millenarismo Tukuna”, America Latina, VI, pp. 43-61.

Del Pozzo, Bartolomeo (1725), Ruolo generale dei cavalieri gerosolimitani della veneranda Lingua d'Italia, Turín.

Díaz Del Castillo, Bernal (1877), Histoire veridique de la conquete de la Nouvelle Espagne, D. JOURDANET (TRAD.), con introducción y selección de textos por Bernard Grunberg, cartas de Pierre Simonet, París.

Du Tertre, Jean Baptiste (1654), Histoire générale des isles de S. Christophe, de la Guadeloupe, de la Martinique et autres dans l'Amerique, où l'on verra l'establissement des colonies françaises dans ces isles, París.

- (1667-1671), Histoire générale des Antilles habitées par les François, París.

Duchet, Michèle (1971) Le origini dell'antropologia. L'ideologia coloniale del Settecento, Bari.

DuRKHEIM, Émile (2005), Le forme elementari della vita religiosa, Roma.

EliAde, Mircea (1978), Les chamanisme et les techniques archaiques de l'extase, París.

- (2005) Il Sacro e il Profano, Turín.

Filoràmo, Giovanni (1997), Storia delle Religioni. 5. Religioni dell'America precolombiana e dei popoli indigeni, Bari.

FOURnIER, Paul (1932), Les voyageurs naturalistes du clergé français avant la Révolution, París.

FrezIER, Amédée-François (1732), Relation du voyage de la Mer du Sud aux cotes du Chily et du Pérou, fait pendant les années 1712, 1713 et 1714, dedié à S. A. R. Monseigneur le Duc d'Orléans Régent du Royaume, avec une réponse à la Préface critique du livre intitulé, Journal des observations physique, Mathématique et Botaniques $d u$ R. P. Feuillée contre la Relation du Voyage de la Mer du Sud et une chronologie des Vicerois du Pérou depuis son établissement jusqu'au tems de la Relation du Voyage de la Mer du Sud, par M. Frezier, Ingénieur ordinaire du Roy, ouvrage enrichi de quantité de Planches en taille-douce, Paris.

Guet-Michaud, Isidore (1893), Origines de la Martinique. Le Colonel François de Collart et la Martinique de son temps. Colonisation, sièges, révoltes et combats de 1625 à 1770, Vannes.

HaZARD, Paul (1961), La crise de la conscience européenne: 1680-1715, París.

LANA, Firmiano Arantes y LanA, Luiz Gomes (1986), Il ventre dell'universo en Ernesta Cerulli y Silvano Sabatini (eds.), Palermo. 
LandUCCI, Sergio (1972), I filosofi e i selvaggi: 1580-1780, Bari.

LANTERnARI, Vittorio (1960), Movimenti religiosi di libertà e di salvezza dei popoli oppressi, Milán.

LÉvi-STrauss, Claude (1962), La pensée sauvage, París.

- (1966), Antropologia Strutturale, Milán.

- (1984), Tristes tropiques, París.

LóPez De Gómara, Francisco (1987), La conquista de México, Madrid.

Metraux, Alfred (1931), "Les hommes-dieux chez les Chiriguano et dans

l'Amérique du Sud", Revista del Istituto de Etnologia de la Universidad de Tucumàn, II, Tucumán, pp. 61-91.

— (1971), Religioni e riti magici degli Indiani dell'America Meridionale, Milán.

Mircea, Eliade (1990), Lo Sciamanesimo, Roma.

Monti Della Corte, Alessandro (1969), "L'impero coloniale dell'Ordine di Malta nei Carabi", en "Rivista Araldica", año LXVII, Roma.

MorTiER, Antonin (1903-1920), Histoire des Maitres Généreaux de l'Ordtre des Frères Precheurs, París.

MüLler, Klaus E. (2001), Sciamanismo, Turín.

Perrin, Michel (1986), Il sentiero degli indiani morti. Miti e simboli Goajiro, Milán.

Pettazzoni, Raffaele (1957), L'essere supremo nelle religioni primitive (L'onniscienza di Dio), Turín.

PincKaers, Servais (1985), Le fonti della morale cristiana, Milán.

Rousseau, Jean-Jacques (1964), Discours sur l'origine et les fondements de l'inégalité, in (Euvres complètes, vol. III, París.

SCHADEN, Egon (1988), Le religioni dei popoli senza scrittura, en Henri-Charles Puech (ed.), Storia delle religioni, trad. it. Bari.

SHAPIRO, Judith (1987), "From "Tupa to the Land without Evil: the Christanization of Tupi-guarani Cosmology", American Ethnologist, XIV/1, Washington, pp. 126-139.

ZERRIES, Otto Krickeberg (1966), Religioni dell'America precolombiana, Milán. 